\title{
Magnetohydrodynamic Boundary Layer Flow of a Viscoelastic Fluid Past a Nonlinear Stretching Sheet in the Presence of Viscous Dissipation Effect
}

\author{
Ahmad Banji Jafar ${ }^{1,2}$, Sharidan Shafie ${ }^{2}$ and Imran Ullah ${ }^{3, *}$ \\ 1 Department of Mathematics, Kebbi State University of Science and Technology, Aliero, \\ P.M.B. 1144 Birnin Kebbi, Kebbi State, Nigeria \\ 2 Department of Mathematical Sciences, Faculty of Science, Universiti Teknologi Malaysia, \\ 81310 Skudai, Johor Bahru, Malaysia \\ 3 College of Civil Engineering, National University of Sciences and Technology, 44000 Islamabad, Pakistan \\ * Correspondence: ullahimran14@gmail.com
}

Received: 30 May 2019 ; Accepted: 19 July 2019; Published: 2 August 2019

\begin{abstract}
This paper numerically investigates the viscous dissipation effect on the boundary layer flow of an electrically-conducting viscoelastic fluid (Walter's B liquid) past a nonlinear stretching sheet. The partial differential equations governing the flow problem are transformed into ordinary differential equations through similarity variables. The transformed equations are then solved using the Keller box method. A careful evaluation of the influence of the pertinent parameters on the velocity field and temperature distributions through various plots is done for the prescribed surface temperature (PST) and prescribed heat flux (PHF) boundary conditions. The computed coefficient of skin friction, the rate of heat transfer (Nusselt number), and the temperature at the wall are also presented in tabular form. It is revealed from this table that the magnitude of the heat transfer is reduced with the increase in the Eckert number $E c$, viscoelastic parameter $K$, and magnetic parameter $M$ for the PST case by about $12 \%, 20 \%$, and $29 \%$, respectively. Similarly, the temperature at the wall for the PHF case also decreases with the increase in $E c$ and $M$ by about $8 \%$ and $24 \%$, respectively. It is obvious that the application of the PST condition excels at keeping the viscoelastic fluid warmer than the PHF condition. This implies that applying the PHF condition is better for cooling the sheet faster. The temperature at the wall is unchanged with the changes in the pertinent parameters in the PST case, and it is ascertained that the present results are in close agreement with the previous published results.
\end{abstract}

Keywords: nonlinear stretching sheet; viscoelastic fluid; MHD; viscous dissipation

\section{Introduction}

The existence of the closed-form solution, the simplicity of the mathematical expression, and the numerous applications, such as plastic sheet extrusion, drawing of plastic films, metallic plate cooling, and the glass blowing of the boundary layer flow past a stretching sheet, have received much attention in recent years. In the process of manufacturing the sheets (metal and plastic), it is required that the melt materials from a slit be stretched continuously until the required thickness is achieved. However, the desired final product of the production process largely depends on the rate at which the sheet cools. The rate of cooling is fundamentally influenced by the type of fluid adjacent to the boundary layer surface [1,2]. The rate at which the sheet is stretched and the rate at which it cools are the two major mechanisms that influence the mechanical properties of the desired product. Similarly, the behaviors of the fluid flows and heat transfer induced by elongating or a moving sheet play a vital role in an industrial process [3]. 
Many researchers have shown keen interest in the study of flow past a stretching sheet, since the work of Crane [4] on the flow past a flat plate. However, Gupta and Gupta [5] observed that the sheet stretching is not always continuous and, hence, may not necessarily conform to the linear speed. For instance, the stretching of the plastic sheet is inextensible and therefore nonlinear. In view of this, Kumaran and Ramanaiah [6], for the first time, presented a note on two-dimensional boundary layer flow past a stretching sheet. They considered the stretching velocity to be quadratic polynomial and obtained a closed-form solution for the problem. Later, the work of Gupta and Gupta [5] was extended by Vajravelu [7] for a nonlinear stretching sheet. He observed that shear stress is an increasing function of the nonlinear stretching sheet parameter. However, an analytical solution of viscous flow past a nonlinear stretching sheet was also solved by Vajravelu and Cannon [8]. They reported that the fluid velocity is a decreasing function of the nonlinear stretching parameter. On the other hand, Cortell [9] numerically extended and studied this problem using the Runge-Kutta method by considering the effect of viscous dissipation with non-isothermal boundary conditions. He reported that an increase in the nonlinear stretching parameter increases the rate of heat transfer. Similarly, Cortell [10] studied the effect of thermal radiation on an induced quiescent fluid past a nonlinear stretching sheet. It was observed from his report that an increase in the radiation parameter reduces the thickness of the thermal boundary, and hence, the heat transfer rate grows.

One of the mechanisms that influence the rate at which heat is being transported in the flow system is the presence of a magnetic field (such as liquid metals, plasma, electrolyte, or salt water) in such flow problem. The concept of such electrically-conducting fluids is known as magnetohydrodynamic (MHD) fluids and has many applications in engineering processes such as MHD power generators, thermal insulators, MHD pumps, and cooling of nuclear reactors [11]. Furthermore, the presence of a magnetic field in the flow problems plays a vital role in controlling the rate of cooling. In view of these important applications of MHD flows past a stretching sheet, many studies [12-14] were conducted by incorporating the magnetic field into the flow problem. Prasad et al. [15] examined the effect of heat generation on the MHD power law flow over a nonlinear stretching sheet. Their results showed that an increase in the power-law index parameter increased the momentum boundary layer thickness and reduced the thickness of the thermal boundary layer. On the other hand, Ullah et al. [16] analyzed the effects of a chemical reaction in the presence of heat generation/absorption and thermal radiation with convective boundary conditions on an unsteady mixed convection flow of Casson fluid over a nonlinear stretching sheet. In the same vein, Ullah et al. [17] used the Keller-Box numerical scheme method to study the effect of a chemical reaction on an electrically-conducting Casson fluid flow past a nonlinear stretching sheet. Furthermore, Hayat et al. [18] analyzed the magnetohydrodynamic Walters' $B$ nanofluid past a nonlinear stretching sheet. They discovered that the rate of heat transfer and the thermal field are enhanced with the increase in temperature ratio.

A viscoelastic fluid is one of the classes of a non-Newtonian fluids that possesses double effect properties (i.e., heat transfer reduction and drag reduction properties), in addition to its properties of exhibiting both viscosity and elasticity, thereby leading to its numerous applications in polymer industries, for instance paper production, production of glass fiber, extrusion processes, thinning and annealing of copper wires, and the production of artificial fibers and plastic film $[19,20]$. One of the pioneering works of the study of the viscoelastic fluid past a stretching surface was investigated by Rajagopal et al. [21]. They observed from their results that there is a decrease in the skin friction coefficient with the increase in the viscoelastic parameter. Later, Dandapat and Gupta [22] extended this work by including heat transfer in the flow problem. Furthermore, Cortell [23] analytically investigated the influence of a magnetic field on viscoelastic fluid induced by a stretching sheet. His results showed that the velocity boundary layer thickness is thicker in second-grade fluid compared to that of Walter's $B$ liquid and observed that the viscoelasticity parameter influences both the viscoelastic fluids.

MHD viscoelastic fluid flow over a stretching sheet plays a vital role in chemical engineering, the metallurgy industry, the polymer extrusion process, the manufacturing of plastic sheets, the drawing of wires and plastic films, the cooling of metallic sheets, and petroleum engineering [23]. However, 
Andersson [24] studied MHD viscoelastic fluid flow over a stretching sheet. He reported from his findings that both viscoelastic and magnetic parameters have the same effect in the fluid flow problem. The radiative effect on MHD viscoelastic fluid flow past a stretching sheet was examined by Char [25]. Likewise, Prasad et al. [26] examined the behavior of an electrically-conducting viscoelastic fluid and heat transfer over a stretching sheet. They noticed that an increase in the magnetic parameter leads to a significant decrease in the wall temperature profile and the velocity gradient. Moreover, an exact solution of a viscoelastic fluid past a stretching sheet with a heat source and viscous dissipation was studied by Abel et al. [27]. Later, Abel et al. [28] examined MHD viscoelastic fluid flow past a stretching sheet and found that the surface temperature of the flow diminishes with the increase in the viscoelasticity. Furthermore, the flow of a viscoelastic fluid induced by a nonlinear stretching sheet using the optimal homotopy analysis method was studied by Mustapha [29].

Besides the importance of a magnetic field in the boundary layer flow and heat transfer is the presence of viscous dissipation in the energy equation. Viscous dissipation plays a significant role similar to that of the energy source, which changes the distribution of the temperature and thereby the rate of heat transfer. This process finds its applications in the flow of oil products through ducts and in polymer processing. The viscous dissipation effect and variable surface temperature on viscous flow past a stretching sheet were examined by Cortell [9]. He explained that the temperature of the fluid rises with an increase in the Eckert number. In the same vein, Abel et al. [30] analyzed the Ohmic and viscous dissipation effect on the MHD boundary layer flow of a viscoelastic fluid past a linear stretching sheet. They observed from their study that the fluid temperature in both the PST and PHF cases amplified with the increase in viscous dissipation parameter. The effects of viscous dissipation and thermal radiation on two-dimensional viscous flow over a nonlinear stretching sheet was addressed numerically through a similarity solution by Cortell [31]. He showed that an increase in thermal radiation and Eckert number leads to the increase in the temperature distribution. A Casson fluid flow over a nonlinear stretching sheet was studied by Medikare et al. [32]. The effects of the heat source/sink and viscous dissipation on magnetohydrodynamic non-Newtonian fluid flow in the presence of Cattaneo-Christov heat flux was examined by Ramandevi et al. [33]. Recently, the effect of joule heating and viscous dissipation on an electrically-conducting tangent hyperbolic nanofluid was examined by Atif et al. [34]. It was reported in their work that the Eckert number and slip parameter enhanced the thermal and concentration fields.

From the above reviews, it is perceived that no consideration has been given to an electrically-conducting viscoelastic fluid over a nonlinear stretching sheet with the viscous dissipation effect. This provides the enthusiasm for the present work, in which the effects of power law surface temperature and power law surface heat flux on the characteristics of the heat transfer of an MHD viscoelastic fluid past a nonlinear stretching sheet in the presence of viscous dissipation are investigated. The unconditionally stable Keller box method was employed in solving the transformed ordinary differential equation by considering non-isothermal boundary conditions. This boundary condition is applicable in an engineering process where the temperature in not constant.

\section{Constitutive Equation}

The rheological equation of state, which is also known as the constitutive equation, describes the relationship between strain, stress, and their time dependence. According to Newtons's law of viscosity "the stress is often proportional to the strain rate",

$$
\tau=\mu \frac{\partial u}{\partial y}
$$

where, $\tau, \mu$, and $\frac{\partial u}{\partial y}$ respectively represent the shear stress, the dynamic viscosity, and the velocity gradient or rate of the strain. Thus, any fluid that does not obey Newtons's law of viscosity is termed as a non-Newtonian fluid. Examples of such fluids are a Casson fluid, a viscoelastic fluid, a power law fluid, and many more. There is no single constitutive equation that describes the behaviors of 
non-Newtonian fluids due their diverse nature. However, amongst the numerous non-Newtonian fluids' models is Walter's B viscoelastic fluid model. This model has a constitutive equation of the form $[35,36]$ :

$$
\mathbf{T}=-p \mathbf{I}+2 \mu_{0} \mathbf{e}-2 k_{0} \frac{\delta \mathbf{e}^{\prime}}{\delta t}
$$

The Cauchy stress tensor $\mathbf{T}$ is expressed in terms of scalar pressure $p$, identity tensor $\mathbf{I}$, dynamic viscosity $\mu_{0}$, short memory coefficient $k_{0}$, and the convected differentiation of the strain rate $\frac{\delta \mathbf{e}^{\prime}}{\delta t}$, while the strain rate tensor $\mathbf{e}$ is defined in terms of the velocity vector $\mathbf{u}$ as:

$$
\mathbf{e}=\nabla \mathbf{u}+(\nabla \mathbf{u})^{T}
$$

It is convenient to represent (3) in the form of matrix suffix notation as:

$$
e_{i j}=\frac{1}{2}\left(\frac{\partial u_{i}}{\partial x_{j}}+\frac{\partial u_{j}}{\partial x_{i}}\right)
$$

where $i$ and $j$ can take values of one and two for two-dimensional flows, and $\frac{\delta \mathbf{e}^{\prime}}{\delta t}$ is expressed as:

$$
\frac{\delta \mathbf{e}^{\prime}}{\delta t}=\frac{\delta e}{\delta t}+\mathbf{u} \cdot \nabla \mathbf{e}-\mathbf{e} \cdot \nabla \mathbf{u}-(\nabla \cdot \mathbf{u})^{T} \cdot \mathbf{e}
$$

Here, $\mathbf{u}$ denotes the velocity vector. Furthermore, the generalized constitutive equation for Walter's B viscoelastic fluid can be expressed as:

$$
\mathbf{T}=\left(\begin{array}{ccc}
\tau_{x x} & \tau_{x y} & 0 \\
\tau_{y x} & \tau_{y y} & 0
\end{array}\right)=-p \mathbf{I}+2 \mu_{0} \mathbf{e}-2 k_{0}\left[\frac{\delta e}{\delta t}+\mathbf{u} \cdot \nabla \mathbf{e}-\mathbf{e} \cdot \nabla \mathbf{u}-(\nabla \cdot \mathbf{u})^{T} \cdot \mathbf{e}\right]
$$

Lastly, the Cauchy equation of motion is given by (see Jaluria [37]):

$$
\rho \frac{D \mathbf{u}}{D t}=\nabla \cdot \mathbf{T}+\mathbf{F}
$$

where $\rho$ is the fluid density, $\frac{D \mathbf{u}}{D t}$ is material derivative, $\mathbf{T}$ is the Cauchy stress tensor and $\mathbf{F}=\left(F_{x}, F_{y}, 0\right)$ is the body force. Following Ahmad et al. [38], the body force $\mathbf{F}$ can be expressed as $\mathbf{F}=\rho \mathbf{g}+\mathbf{J} \times \mathbf{B}$, where $\mathbf{g}$ is the gravitational field, $\mathbf{J}$ is the current density, $\mathbf{B}=(0, B, 0)$ is the magnetic force and $\mathbf{J} \times \mathbf{B}$ is the Lorentz force and is simplified as

$$
\mathbf{F}=\sigma B^{2} \mathbf{u}
$$

where $\sigma$ is the electrical conductivity.

\section{Flow Problem Formulation}

A two-dimensional electrically-conducting viscoelastic Walter's B fluid flow in the presence of viscous dissipation over a vertical nonlinear stretching sheet at $y=0$ is considered in this problem. The sheet was assumed to vary nonlinearly with the velocity $U_{w}=a x^{n}$, where $n$ represents the nonlinear stretching parameter and $a(>0)$ is the stretching rate constant. This fluid flow obeys the constitutive Equation (6). The surface of the sheet was held at power law surface temperature $T_{w}=T_{\infty}+b x^{(2 n-1)}$ and power law heat flux $-k \frac{\partial T}{\partial y}=c x^{2 n-1}$, where $n$ is the parameter for surface temperature, $b(>0)$ and $c(>0)$ are constants, and $T_{\infty}$ is the ambient temperature of the viscoelastic fluid. The variable magnetic field $B(x)=B_{0} x^{(2 n-1)}$ was applied normal to the sheet as shown in Figure 1 with $x y$-Cartesian coordinates in the horizontal and vertical direction. The steady two-dimensional continuity and Cauchy momentum equations are [36,37,39,40]: 


$$
\begin{gathered}
\frac{\partial u}{\partial x}+\frac{\partial v}{\partial y}=0 \\
\rho\left(u \frac{\partial u}{\partial x}+v \frac{\partial u}{\partial y}\right)=-\frac{\partial p}{\partial x}+\frac{\partial \tau_{x x}}{\partial x}+\frac{\partial \tau_{x y}}{\partial y}+F_{x} \\
\rho\left(u \frac{\partial v}{\partial x}+v \frac{\partial v}{\partial y}\right)=-\frac{\partial p}{\partial y}+\frac{\partial \tau_{y x}}{\partial x}+\frac{\partial \tau_{y y}}{\partial y}+F_{y}
\end{gathered}
$$

where $\tau_{x x}, \tau_{x y}, \tau_{y x}$, and $\tau_{y y}$ are the components of the stress matrix, $\frac{\partial \tau_{x x}}{\partial y}$ and $\frac{\partial \tau_{y y}}{\partial y}$ are elastic terms, while $\frac{\partial \tau_{x y}}{\partial y}$ and $\frac{\partial \tau_{y y}}{\partial y}$ are viscous terms.

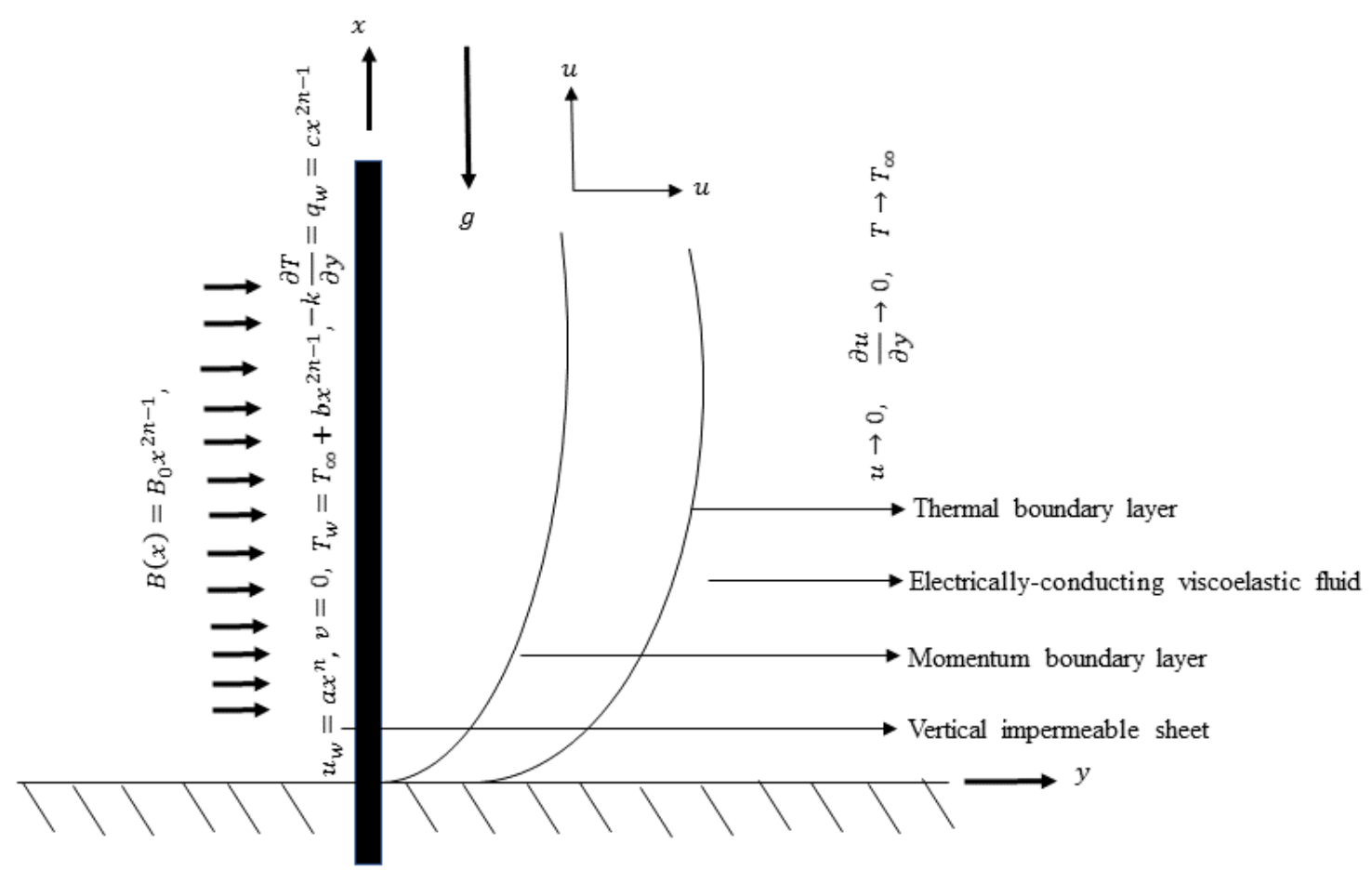

Figure 1. A schematic diagram showing the flow geometry.

To simplify Equations (10) and (11), we need to find $\frac{\partial \tau_{x x}}{\partial y}, \frac{\partial \tau_{y y}}{\partial y}, \frac{\partial \tau_{x y}}{\partial y}$, and $\frac{\partial \tau_{y y}}{\partial y}$ through Equation (6) and substitute it back into (10) and (11) to get:

The $x$ momentum equation:

$$
\begin{gathered}
\rho\left(u \frac{\partial u}{\partial x}+v \frac{\partial u}{\partial y}\right)=-\frac{\partial p}{\partial x}+\mu_{0}\left(\frac{\partial^{2} u}{\partial x^{2}}+\frac{\partial u^{2}}{\partial y^{2}}\right)-k_{0}\left(u \frac{\partial^{3} u}{\partial x^{3}}+u \frac{\partial^{3} u}{\partial x \partial y^{2}}+v \frac{\partial^{3} u}{\partial x^{2} \partial y}+v \frac{\partial^{3} u}{\partial y^{3}}+3 \frac{\partial u}{\partial x} \frac{\partial^{2} v}{\partial x \partial y}\right) \\
+k_{0}\left(\frac{\partial u}{\partial x} \frac{\partial^{2} u}{\partial y^{2}}-\frac{\partial u}{\partial y} \frac{\partial^{2} u}{\partial x \partial y}-\frac{\partial u}{\partial y} \frac{\partial^{2} v}{\partial x^{2}}-2 \frac{\partial v}{\partial x} \frac{\partial^{2} u}{\partial y \partial x}+F_{x}\right)
\end{gathered}
$$

The $y$ momentum equation:

$$
\begin{gathered}
\rho\left(u \frac{\partial v}{\partial x}+v \frac{\partial v}{\partial y}\right)=-\frac{\partial p}{\partial y}+\mu_{0}\left(\frac{\partial^{2} v}{\partial x^{2}}+\frac{\partial v^{2}}{\partial y^{2}}\right)-k_{0}\left(u \frac{\partial^{3} v}{\partial x^{3}}+u \frac{\partial^{3} v}{\partial x \partial y^{2}}+v \frac{\partial^{3} v}{\partial y \partial x^{2}}+v \frac{\partial^{3} v}{\partial y^{3}}+3 \frac{\partial v}{\partial y} \frac{\partial^{2} u}{\partial x \partial y}\right) \\
k_{0}\left(+\frac{\partial v}{\partial y} \frac{\partial^{2} v}{\partial x^{2}}-\frac{\partial v}{\partial x} \frac{\partial^{2} v}{\partial y \partial x}-\frac{\partial v}{\partial x} \frac{\partial^{2} u}{\partial y^{2}}-2 \frac{\partial u}{\partial y} \frac{\partial^{2} v}{\partial x \partial y}+F_{y}\right)
\end{gathered}
$$


Following boundary layer theory, we can assume an order of magnitude approach on each term of Equations (12) and (13) as (see Beard and Walter [35]):

$$
O(u)=1, O(x)=1, O(v)=\delta, O(v)=\delta, O(\rho)=1, O\left(k_{0}\right)=\delta^{2}, O\left(\mu_{0}\right)=\delta^{2}, \text { and } O\left(B^{2}\right)=\delta^{2}
$$

Simplify boundary layer Equations (12) and (13) with these orders of magnitude to obtain:

$$
\begin{gathered}
\rho\left(u \frac{\partial v}{\partial x}+v \frac{\partial v}{\partial y}\right)=-\frac{\partial p}{\partial x}+v \frac{\partial^{2} u}{\partial y^{2}}-k_{0}\left\{u \frac{\partial^{3} u}{\partial x \partial y^{2}}+\frac{\partial u}{\partial x} \frac{\partial^{3} u}{\partial y^{2}}-\frac{\partial u}{\partial y} \frac{\partial^{2} u}{\partial x \partial y}+v \frac{\partial^{3} u}{\partial y^{3}}\right\}+\sigma B^{2} u \\
\frac{\partial p}{\partial y}=0
\end{gathered}
$$

Equation (15) gives the momentum boundary layer equation for the viscoelastic fluid with the magnetic field. Since the vertical plate is directed along the $x$-axis, the pressure gradient $\frac{\partial p}{\partial x}=0$. Hence, the momentum boundary layer governing equations for two-dimensional electrically-conducting viscoelastic fluid are given by:

$$
u \frac{\partial v}{\partial x}+v \frac{\partial v}{\partial y}=v \frac{\partial^{2} u}{\partial y^{2}}-\frac{k_{0}}{\rho}\left\{u \frac{\partial^{3} u}{\partial x \partial y^{2}}+\frac{\partial u}{\partial x} \frac{\partial^{3} u}{\partial y^{2}}-\frac{\partial u}{\partial y} \frac{\partial^{2} u}{\partial x \partial y}+v \frac{\partial^{3} u}{\partial y^{3}}\right\}+\frac{\sigma}{\rho} B^{2}(x) u
$$

subject to the following flow boundary conditions:

$$
u=U_{w}(x)=a x^{n}, \quad v=0, \quad \text { at } y=0
$$

and:

$$
u \rightarrow 0, \quad \frac{\partial u}{\partial y} \rightarrow 0, \quad \text { as } y \rightarrow \infty
$$

where $x$ is parallel along the sheet, $y$ is the direction perpendicular to the sheet, $u$ and $v$ are the horizontal and vertical velocity in the $x y$-direction, respectively, $v$ is the kinematic viscosity, and $k_{o}$ is the coefficient of the viscoelasticity, while all other physical parameters are as defined above.

To reduce the complexity of the system of the governing equations into the system of ordinary differential equations, a similarity transformation in the following form is introduced as (see Vajravelu [7]),

$$
\eta=\sqrt{\frac{(n+1) u}{2 v x}} y \quad \text { and } \quad \psi(x, y)=\sqrt{\frac{2 v u x}{(n+1)}} f(\eta)
$$

where $\psi(x, y)$ denotes the stream function and is defined by:

$$
u=\frac{\partial \psi}{\partial y} \quad \text { and } \quad v=-\frac{\partial \psi}{\partial x}
$$

Substituting Equations (19) and (20) into Equations (17) and (18) yields dimensionless ordinary differential equations:

$$
f^{\prime \prime \prime}+f f^{\prime \prime}-\left(\frac{2 n}{n+1}\right) f^{\prime 2} f^{\prime}-K\left\{(3 n-1) f^{\prime} f^{\prime \prime \prime}-\left(\frac{3 n-1}{2}\right) f^{\prime \prime 2}-\left(\frac{n+1}{2}\right) f f^{i v}\right\}-M\left(\frac{2}{n+1}\right)=0
$$

subject to the following dimensionless boundary conditions:

$$
\begin{array}{llll}
f(\eta)=0, & f^{\prime}(\eta)=1 & \text { at } & \eta=0 \\
f^{\prime}(\eta) \rightarrow 0, & f^{\prime \prime}(\eta) \rightarrow 0 & \text { as } & \eta \rightarrow \infty
\end{array}
$$


where the prime represents the derivative of $f$ with respect to $\eta$ and the dimensionless quantities in these equations are nonlinear sheet parameter $n$, viscoelastic parameter $K$, and magnetic parameter $M$, which are defined as:

$$
K=\frac{a x^{n-1}}{\rho v} \quad \text { and } \quad M=\frac{\sigma B_{0}^{2}}{\rho a}
$$

The physical quantity of interest is the coefficient of skin friction $C_{f}$ at the stretched surface and defined as:

$$
C_{f}=\frac{\tau_{w}}{\rho u_{w}^{2}}
$$

where $\tau_{w}$ is the wall shear stress from the plate and is given by:

$$
\tau_{w}=\mu_{0}\left(\frac{\partial u}{\partial y}\right)_{y=0}-k_{0}\left(u \frac{\partial^{2} u}{\partial u \partial y}+v \frac{\partial^{2} u}{\partial y^{2}}-2 \frac{\partial u}{\partial y} \frac{\partial v}{\partial y}\right)_{y=0}
$$

\section{Heat Transfer Analysis}

For the analysis of heat transfer, two cases of the heating process are considered, i.e.,

(i) Prescribed surface temperature (PST)

(ii) Prescribed heat flux (PHF)

These non-isothermal conditions are applicable in industrial and engineering processes where the temperature is not constant. The energy equation with the viscous dissipation term is given by (see Cortell [9]):

$$
u \frac{\partial T}{\partial x}+v \frac{\partial T}{\partial y}=\alpha \frac{\partial^{2} T}{\partial y^{2}}+\frac{v}{C_{p}}\left(\frac{\partial u}{\partial y}\right)^{2}
$$

where $T, \alpha$, and $\rho C_{p}$ are respectively the temperature, thermal diffusivity, and specific heat capacity of the fluid at constant pressure, while all other physical parameters are as defined above. The thermal boundary conditions depend on the type of heating process under consideration. The momentum Equation (15) and the energy Equation (26) are decoupled and thereby solved sequentially.

\subsection{Case I: Prescribed Surface Temperature}

For this case, the thermal boundary conditions are:

$$
T=T_{w}=T_{\infty}+b x^{2 n-1} \quad \text { at } y=0
$$

and:

$$
T \rightarrow \infty \quad \text { as } y \rightarrow \infty
$$

where $n$ stands for wall temperature parameter, and when $n=\frac{1}{2}$, we have the isothermal boundary condition. The dimensionless temperature $\theta(\eta)$ is assumed to be of the form:

$$
\theta(\eta)=\frac{T-T_{\infty}}{T_{w}-T_{\infty}}
$$

Substituting Equations (19), (20), (27), and (28) into Equation (26) gives:

$$
\theta^{\prime \prime}+\operatorname{Pr}\left\{f \theta^{\prime}-\left(\frac{2(2 n-1)}{n+1}\right) f^{\prime} \theta+E_{c}\left(f^{\prime \prime}\right)^{2}\right\}=0
$$

also, the boundary conditions (27) become:

$$
\theta(\eta)=1 \quad \text { at } \quad \eta=0
$$




$$
\theta(\eta) \rightarrow 0 \quad \text { as } \quad \eta \rightarrow \infty
$$

Here, $\operatorname{Pr}$ and Ec represent the Prandtl and Eckert numbers, respectively, defined as:

$$
\operatorname{Pr}=\frac{v}{\alpha} \quad \text { and } \quad E C=\frac{U^{2} w}{c_{p}\left(T-T_{\infty}\right)}
$$

The physical quantity of interests here is the local Nusselt number $N u_{x}$, which is defined by:

$$
N u_{x}=\frac{x q_{w}}{\alpha}\left(T_{w}-T_{\infty}\right)
$$

where $q_{w}$ is the wall heat flux from the plate and is expressed as:

$$
q_{w}=-k\left(\frac{\partial T}{\partial y}\right)_{y=0}
$$

\subsection{Case II: Prescribed Heat Flux}

For this case, the thermal boundary conditions are:

$$
-k \frac{\partial T}{\partial y}=q_{w}=c x^{2 n-1} \quad \text { at } y=0
$$

and:

$$
T \rightarrow \infty \quad \text { as } y \rightarrow \infty
$$

where $n$ stands for the surface temperature parameter. The dimensionless temperature $g(\eta)$ is assumed to be of the form:

$$
g(\eta)=\frac{T-T_{\infty}}{T_{w}-T_{\infty}}, \quad \text { where } \quad T_{w}-T_{\infty}=\frac{c}{k} x^{2 n-1} \sqrt{\frac{2 v x}{(n+1) u}}
$$

Substitute Equations (19), (20), (34), and (35) into Equation (26) to get dimensionless energy equation for PHF as:

$$
g^{\prime \prime}+\operatorname{Pr}\left\{f g^{\prime}-\left(\frac{2(2 n-1)}{n+1}\right) f^{\prime} g+E_{c}\left(f^{\prime \prime}\right)^{2}\right\}=0
$$

similarly, the corresponding boundary conditions (34) give:

$$
\begin{array}{lll}
g^{\prime}(\eta)=-1 & \text { at } & \eta=0 \\
g(\eta)=0 & \text { as } & \eta \rightarrow \infty
\end{array}
$$

and all other physical parameters are in analogy with those mentioned in case 1, except for the constant $c$, which will be replaced in PHF.

\section{Method of the Solution}

An implicit finite difference scheme known as the Keller box method is used in solving the ordinary differential Equations (21), (29), and (36) with their respective boundary conditions (22), (30), and (32). This method is very accurate, useful, efficient, and unconditionally stable. More explanations of this method can be found in [41,42], and it involves four basic steps:

(i) the transformed ordinary equations are expressed in the system of first order equations in $\eta$.

(ii) the resulting first order system of equations is written as finite difference equations using the central difference method about the mid-point. 
(iii) the resulting finite difference equations are linearized by Newton's method.

(iv) the linearized system of equations is written in matrix vector form and then solved using the block tri-diagonal elimination method.

The step size $\Delta \eta=0.02$ was used to achieve the numerical solution, and the procedures were repeated until the convergence to a specified accuracy was achieved.

\section{Results and Discussion}

In order to examine the effects of nonlinear stretching parameter $n$, viscoelastic parameter $K$, magnetic parameter $M$, Eckert number $E c$, and Prandtl number $P r$, on boundary flow of an electrically-conducting viscoelastic fluid past a nonlinear stretching sheet, results from the graphs for velocity and temperature profiles, as well as the numerical results of the skin friction coefficient and heat transfer rate (reduced Nusselt number) for the PST and PHF cases are illustrated in tables. To validate the accuracy of the present numerical method, we computed and compared the present results for skin friction coefficient $f^{\prime \prime}(0)$ with different values of $n$ and $K$ with that of Vajravelu [7] and Arnold et al. [43] as displayed in Table 1, heat transfer rate $\theta^{\prime}(0)$ (for the PST case), and the surface temperature $g(0)$ (for the PHF case) for different values of $\mathrm{Pr}$ with that of Arnold et al. [43] when $E c=0.1$ and $K=0.02$, as shown in Table 2. The current results demonstrated a close agreement with the previous results under some certain conditions. It is also observed from Table 2 that the rate of heat transfer increased with an increase in $\operatorname{Pr}$ for the PST case. This is because fluid with higher $\operatorname{Pr}$ has a comparatively lower thermal conductivity, which decreases the conduction, which in turn increases the variation. This phenomenon reduces the thickness of the thermal boundary layer and increases the heat transfer at the surface. Similarly, the surface temperature reduced with the increase in the $\operatorname{Pr}$ for the PHF case. This implies that an increase in $\mathrm{Pr}$ has a cooling effect on the surface.

Table 3 is introduced to analyze the influence of some physical parameters for $M=0$ and $M=5$ on the coefficient of skin friction $f^{\prime \prime}(0)$, and it is observed from this table that an increase in $n$ and $K$ increased the coefficient of skin friction $f^{\prime \prime}(0)$ significantly. This behavior is also true with the inclusion of a magnetic field $M$ into the flow problem. In Table 4, the variation of the rate of heat transfer $\theta^{\prime}(0)$ and the temperature at the wall $g(0)$ with different values $M, K, E c$, and $P r$ for $n=2$ in both PST- and PHF cases is recorded. It is clear that the magnitude of the heat transfer rate decreased with an increase in $M, K$, and $E c$ and increased significantly with the increase in the value of Prandtl number $\operatorname{Pr}$ for the PST case. Similarly, the temperature at the wall increased with the increase in $E c$ and $M$ and reduced with respect to the increase in $K$. The effect of $K$ was to increase the heat transfer rate for the PST case and the temperature at the surface for the PHF case, while the effect of $E c$ and $M$ was to amplify the heat transfer rate and diminish the temperature at the surface for both the PST- and PHF cases. This implies that the thickness of the thermal boundary layer reduced as $M$ and $E c$ increased, which led to the higher heat transfer rate at the surface, thereby enhancing the temperature $g(\eta)$. Similarly, an increase in $\mathrm{Pr}$ led to the reduction in the thickness of the thermal boundary layer in both cases.

The effects of different dimensionless parameters, such as nonlinear stretching parameter $n$, viscoelastic parameter $K$, magnetic parameter $M$, Eckert number $E c$, and Prandtl number $P r$, for prescribed surface temperature (PST) and prescribed heat flux (PHF) on the electrically-conducting viscoelastic fluid and heat transfer are depicted in Figures 1-13.

Figures 2-4 illustrate the behaviors of velocity and temperature profiles for various values of nonlinear stretching sheet parameter $n$ with and without a magnetic field in the PST and PHF cases. An increase in $n$ decreased the velocity profile, which led to the increase in the coefficient of skin friction. The decrease was high in the presence of a magnetic field, which physically shows the influence of a magnetic field in an electrically-conducting viscoelastic fluid to produce an opposing force known as Lorentz force. This force has the ability of slowing down the fluid flow in the layer region. It is also noticed from Figure 2 that an increase in $M$ decreased the velocity profile. Figures 3 and 4 illustrate that the temperature profiles for PST- and PHF cases increased with the increase in the nonlinear stretching sheet parameter $n$. This implies that the rate of heat transfer reduced with the 
increase in $n$. This phenomenon showed that the thickness of the momentum boundary layer became thinner and thermal boundary thickness became thicker with an increase in $n$. The same behavior of this trend was reported by Vajravelu [7].

Table 1. Comparison of local skin friction $f^{\prime \prime}(0)$ at the wall for the present results and that of Vajravelu [7] when $K=R=Q=E c=0$ with that of Arnold et al. [43] for various values of $K$ when $M=E c=0$.

\begin{tabular}{cccccc}
\hline $\boldsymbol{n}$ & $\boldsymbol{K}$ & $\frac{\boldsymbol{f}^{\prime \prime}(\mathbf{0})}{\bar{V} \text { Vajravelu [7] }}$ & $\frac{f^{\prime \prime}(\mathbf{0})}{\text { Present Results }}$ & $\frac{-f^{\prime \prime}(\mathbf{0})}{\text { Arnold et al. [43] }}$ & $\frac{-f^{\prime \prime}(\mathbf{0})}{\text { Present Results }}$ \\
\hline 0 & - & 1.0000 & 0.9999 & - & - \\
5 & - & 1.1945 & 1.1946 & - & - \\
10 & - & 1.2348 & 1.2346 & - & - \\
- & 0 & - & - & -1.0000 & -1.0004 \\
- & 0.1 & - & - & -1.0041 & -1.0052 \\
- & 0.3 & - & - & -1.1952 & -1.1971 \\
- & 0.5 & - & - & -1.4142 & -1.4147 \\
\hline
\end{tabular}

Table 2. Comparison of the numerical results of the heat transfer rate $-\theta^{\prime}(0)$ and the surface temperature $g(0)$ with the published results of Arnold et al. [43] for the PST- and PHF cases, respectively, for different values of $\operatorname{Pr}$ with $E c=1.0$ and $K=0.02$.

\begin{tabular}{cccccc}
\hline $\operatorname{Pr}$ & \multicolumn{2}{c}{$-\theta^{\prime}(\mathbf{0})$} & & \multicolumn{2}{c}{$g(\mathbf{0})$} \\
\cline { 2 - 3 } \cline { 5 - 6 } $\operatorname{Pr}$ & Arnolds et al. [43] & Present Results & & Arnolds et al. [43] & Present Results \\
\hline 1 & 0.988 & 1.000 & & 1.009 & 1.000 \\
5 & 2.236 & 2.229 & & 0.624 & 0.622 \\
10 & 3.080 & 3.056 & & 0.564 & 0.567 \\
100 & 8.787 & 8.786 & & 0.503 & 0.506 \\
\hline
\end{tabular}

Table 3. Variation of the numerical results for skin friction $-f^{\prime \prime}(0)$ with different values of $M, n$, and $K$.

\begin{tabular}{cccc}
\hline $\boldsymbol{M}$ & $\boldsymbol{n}$ & $\boldsymbol{K}$ & $-\boldsymbol{f}^{\prime \prime}(\mathbf{0})$ \\
\hline 0 & 1 & 0.4 & 1.0590 \\
0 & 2 & 0.4 & 2.1084 \\
0 & 3 & 0.4 & 6.1704 \\
5 & 1 & 0.4 & 2.4888 \\
5 & 2 & 0.4 & 3.3021 \\
5 & 3 & 0.4 & 6.1704 \\
0 & 2 & 0.4 & 2.1084 \\
0 & 2 & 2.0 & 10.2509 \\
0 & 2 & 4.0 & 12.6666 \\
5 & 2 & 0.4 & 3.3021 \\
5 & 2 & 2.0 & 10.1751 \\
5 & 2 & 4.0 & 12.3794 \\
\hline
\end{tabular}

The effect of viscoelastic parameter $K$ on the velocity and temperature profiles is illustrated in Figures 5-7 in the presence and absence of a magnetic field. The momentum boundary layer thickness decreased with the increase in the value of $K$, as shown in Figure 5. This implies that tensile stress enhances the viscoelasticity through a large value of $K$, which has a tendency to increase the adherence to the surface of the momentum boundary layer, thereby reducing the velocity of the fluid. In the same vein, the temperature profile increased with the increase in the value of $K$ in both PST- and PHF cases. Physically, an increase in the viscoelastic normal stress leads to the increase in the thermal boundary layer thickness. This process was the same in both the PST- and PHF cases. However, it is revealed by these figures that the inclusion of a magnetic field increased the thermal boundary thickness a bit higher compared to the case where $M=0$. This result coincides with the results reported by Hayat et al. [18]. 
Table 4. Variation of the numerical values for the rate of heat transfer $-\theta^{\prime}(0)$ and the wall temperature $g(0)$ for PST- and PHF cases for different values of $n, M, K, E c$, and $\operatorname{Pr}$.

\begin{tabular}{|c|c|c|c|c|c|c|c|}
\hline \multirow[b]{2}{*}{$n$} & \multirow[b]{2}{*}{$M$} & \multirow[b]{2}{*}{$K$} & \multirow[b]{2}{*}{$E c$} & \multicolumn{2}{|c|}{$-\theta^{\prime}(0)$} & \multicolumn{2}{|c|}{$g(0)$} \\
\hline & & & & $\operatorname{Pr}=0.7$ & $\operatorname{Pr}=7$ & $P r=0.7$ & $P r=7$ \\
\hline 2 & 0 & 0.4 & 0.1 & 0.968208 & 3.388100 & 0.828806 & 0.201817 \\
\hline 2 & 0 & 0.4 & 0.5 & 0.846103 & 2.595794 & 0.893924 & 0.295620 \\
\hline 2 & 0 & 0.4 & 1.0 & 0.693472 & 1.605411 & 0.975321 & 0.412874 \\
\hline 2 & 0 & 2.0 & 0.1 & 0.772763 & 2.402988 & 0.760442 & 0.183771 \\
\hline 2 & 0 & 2.0 & 0.5 & 0.451428 & -0.365513 & 0.791460 & 0.224805 \\
\hline 2 & 0 & 2.0 & 1.0 & 0.049759 & -3.826139 & 0.830232 & 0.276098 \\
\hline 2 & 5 & 0.4 & 0.1 & 0.681828 & 2.842824 & 1.078284 & 0.266512 \\
\hline 2 & 5 & 0.4 & 0.5 & 0.418812 & 0.959411 & 1.281700 & 0.563798 \\
\hline 2 & 5 & 0.4 & 1.0 & 0.090042 & -1.345851 & 1.535970 & 0.935405 \\
\hline 2 & 5 & 2.0 & 0.1 & 0.563905 & 2.067077 & 0.875843 & 0.213427 \\
\hline 2 & 5 & 2.0 & 0.5 & 0.160478 & -1.345851 & 0.965558 & 0.343080 \\
\hline 2 & 5 & 2.0 & 1.0 & -3.343807 & -5.612011 & 1.077701 & 0.505146 \\
\hline
\end{tabular}

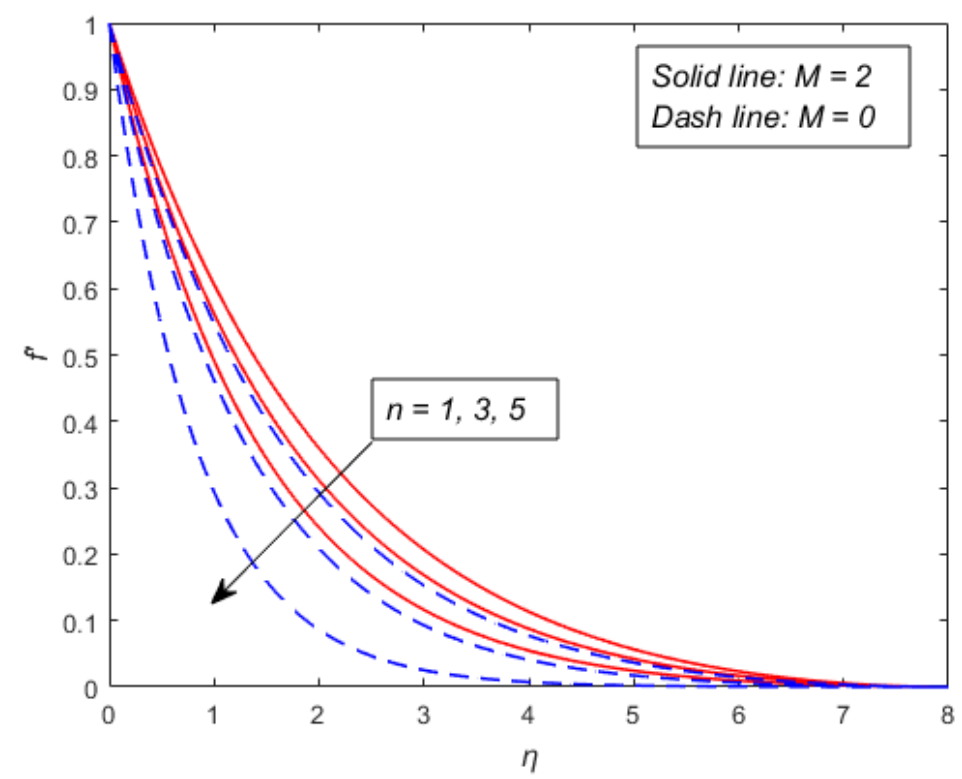

Figure 2. Variation of the velocity profile for different values of nonlinear stretching sheet parameter $n$ and magnetic parameter $M$ for $K=1, \operatorname{Pr}=0.71$, and $E c=0.1$.

The influence of the magnetic field $M$ on the temperature profiles is shown in Figures 8 and 9. It is observed in these figures that the temperature profile increased with the increase in M. Physically, the presence of a magnetic field in an electrically-conducting fluid generates a drag-like body force, which always acts against flow, and as a result, the fluid flow decelerates. This force is known as Lorentz force and has the ability to oppose the fluid motion. The temperature of the fluid is also enhanced due to the resistance offered by this force. This shows the thermal boundary layer thickness was reduced in both the PST- and PHF cases. However, the decrease was more pronounced when $\mathrm{Pr}=0.71$ as compared to when $\operatorname{Pr}=7$. 


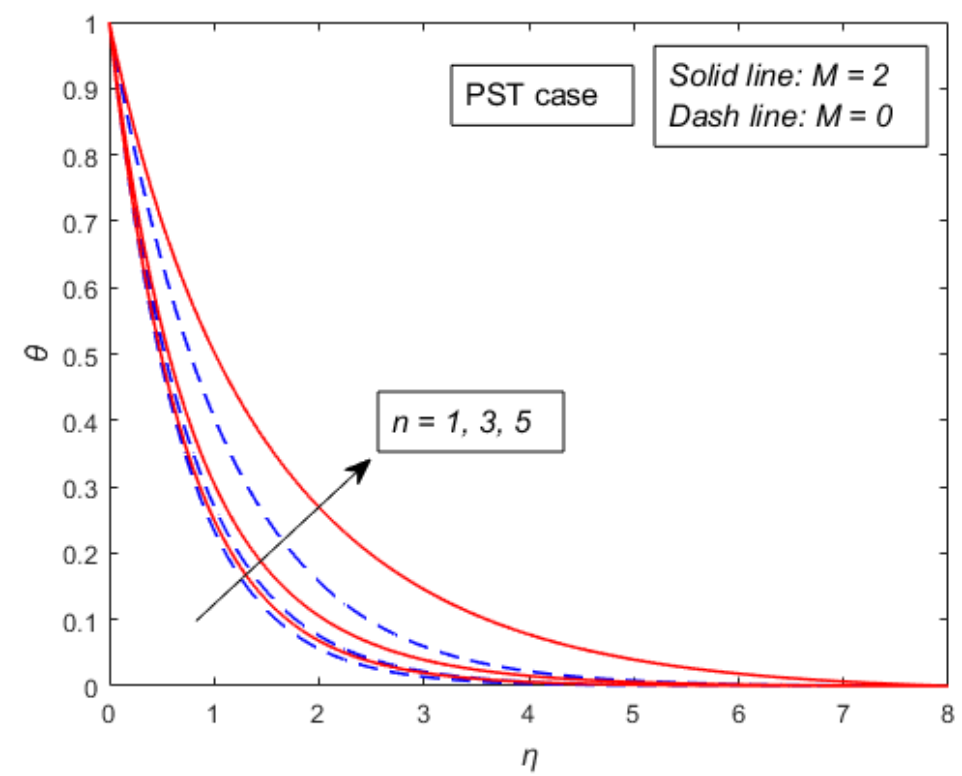

Figure 3. Variation of the temperature profile for different values of nonlinear stretching sheet parameter $n$ and magnetic parameter $M$ for the prescribed surface temperature (PST) case when $K=1, \operatorname{Pr}=0.71$, and $E c=0.1$.

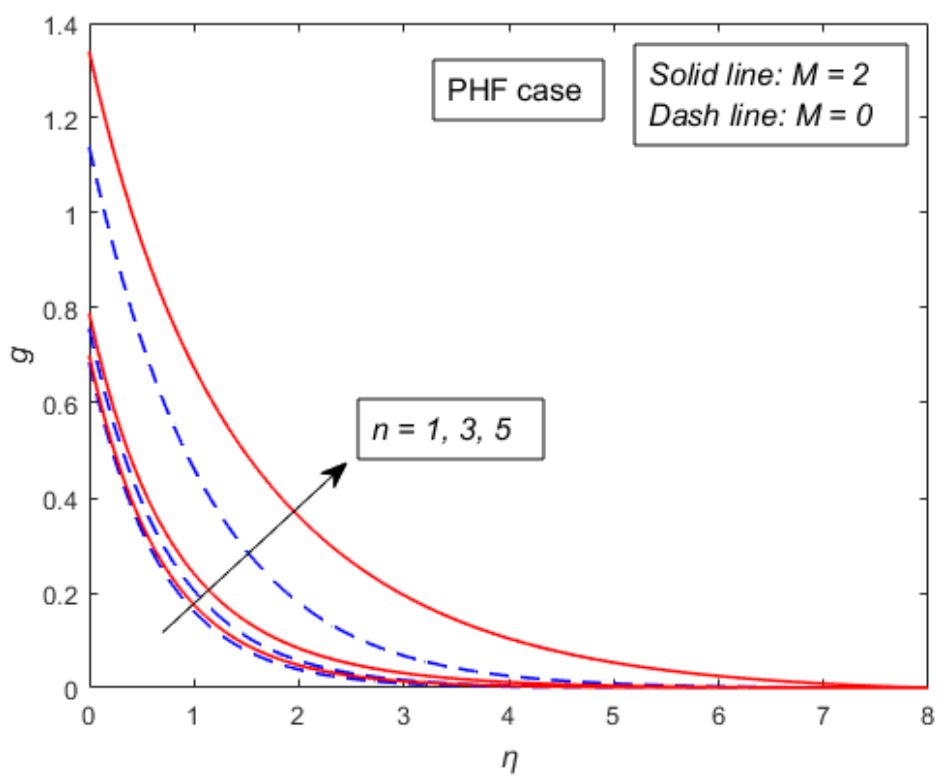

Figure 4. Variation of the temperature profile for different values of nonlinear stretching sheet parameter $n$ and magnetic parameter $M$ for the prescribed heat flux (PHF) case when $K=1, \operatorname{Pr}=0.71$, and $E c=0.1$. 




Figure 5. Variation of the velocity profile for different values of viscoelastic parameter $K$ and magnetic parameter $M$ for $n=3, \operatorname{Pr}=0.71$, and $E c=0.1$.

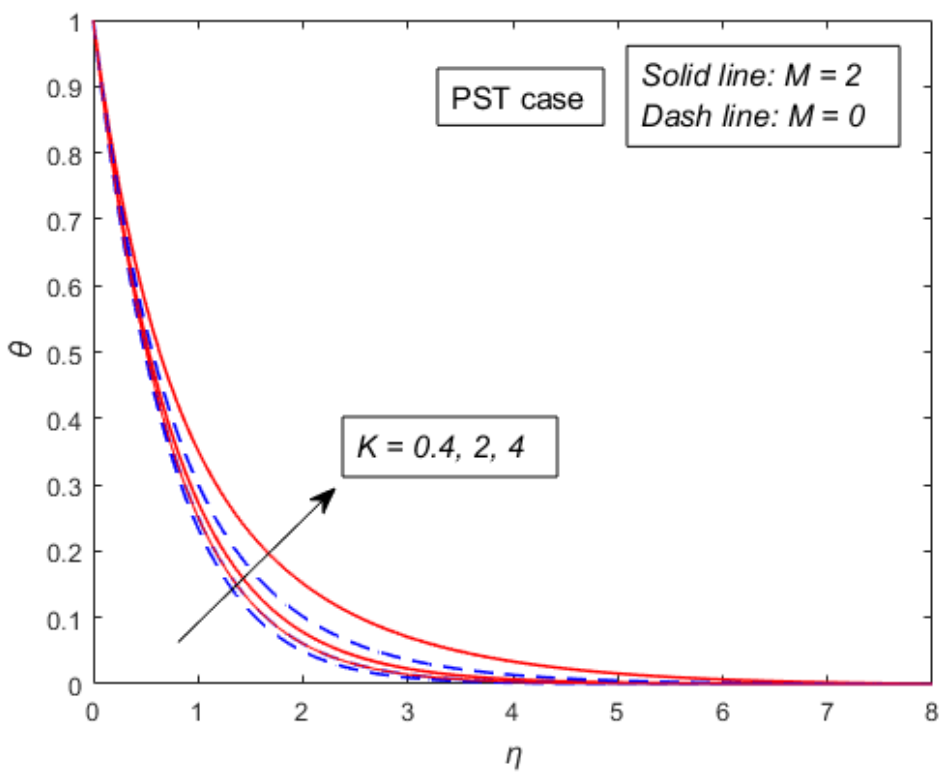

Figure 6. Variation of the temperature profile for different values of viscoelastic parameter $K$ and magnetic parameter $M$ for the PST case when $n=3, P r=0.71$, and $E c=0.1$. 




Figure 7. Variation of the temperature profile for different values of viscoelastic parameter $K$ and magnetic parameter $M$ for the PHF case when $n=3, \operatorname{Pr}=0.71$, and $E c=0.1$.

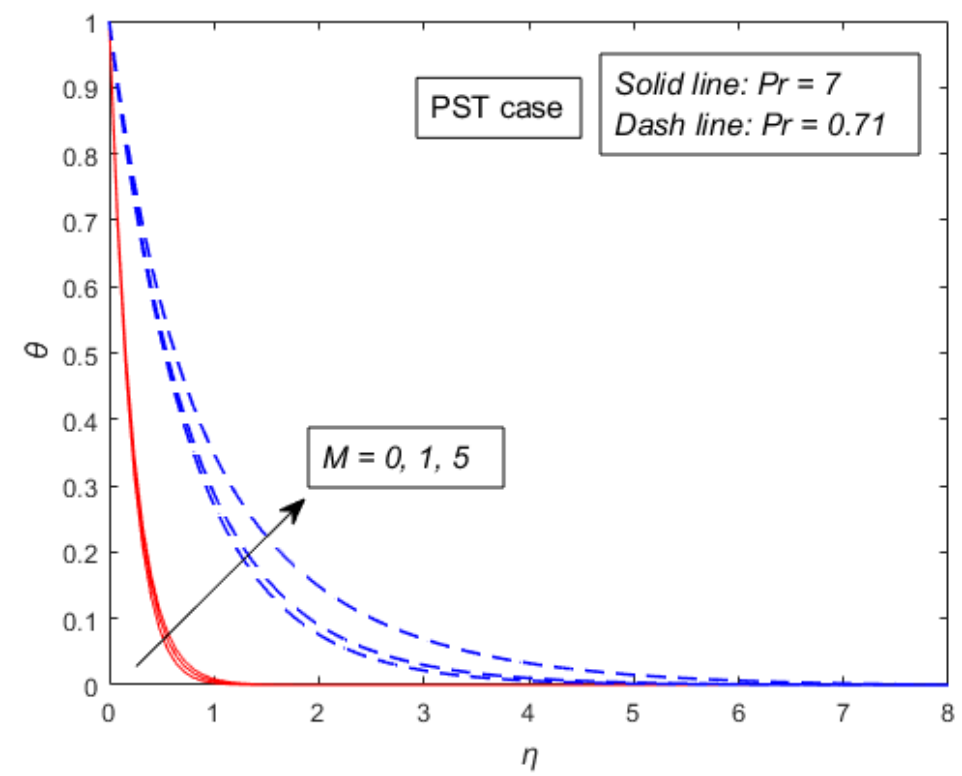

Figure 8. Variation of the temperature profile for different values of magnetic parameter $M$ and Prandtl number $\operatorname{Pr}$ for the PST case when $n=3, K=1$, and $E c=0.1$. 


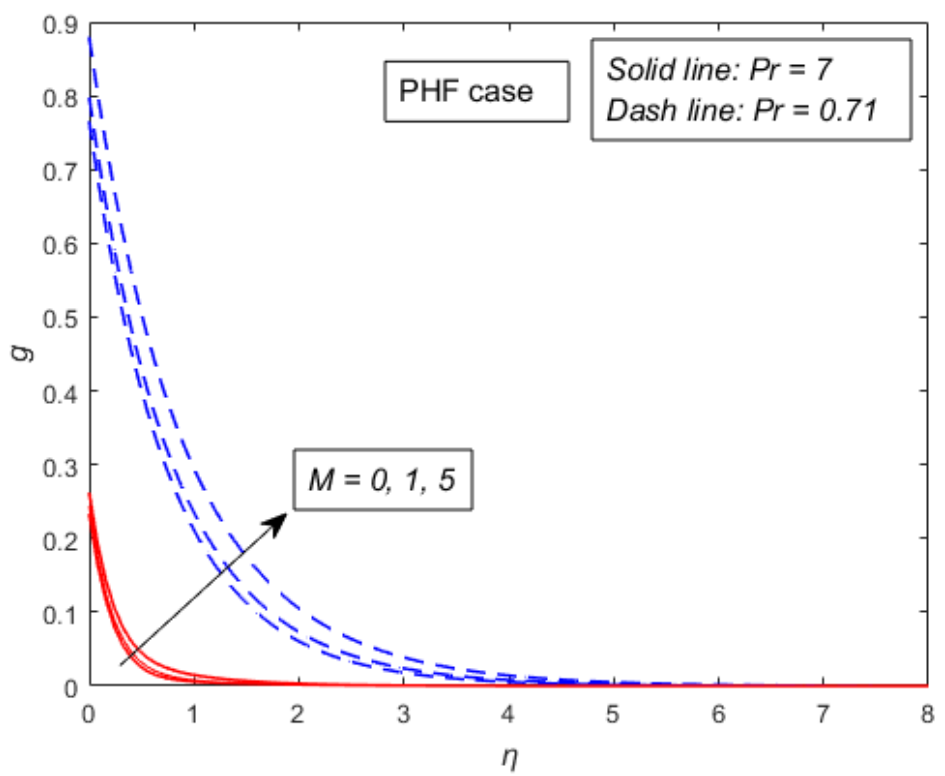

Figure 9. Variation of the temperature profile for different values of magnetic parameter $M$ and Prandtl number $\operatorname{Pr}$ for the PHF case when $n=3, K=1$, and $E c=0.1$.

Figures 10 and 11 depict the effects of Eckert number $E c$ on the temperature profiles in the PSTand PHF cases in the presence of a magnetic field. It is noticed that an increase in the value of the Eckert number amplified the temperature profiles in both cases. The enhancement was higher for a small value of the Prandtl number. The influence of augmenting $E_{c}$ is to improve the temperature distribution in the boundary layer region, thereby increasing the thickness of the thermal boundary layer. This is because heat energy is stored in the fluid due to frictional heating, which arises due to the presence of viscous dissipation. A large value of $E c$ produces more heat in the fluid. We can therefore infer that an increase in Ec improved the temperature of the fluid at any point for the PST- and PHF cases. However, the temperature distribution remained the same at the surface with the variation of the Eckert number for the PST case. A similar behavior was reported by [27].

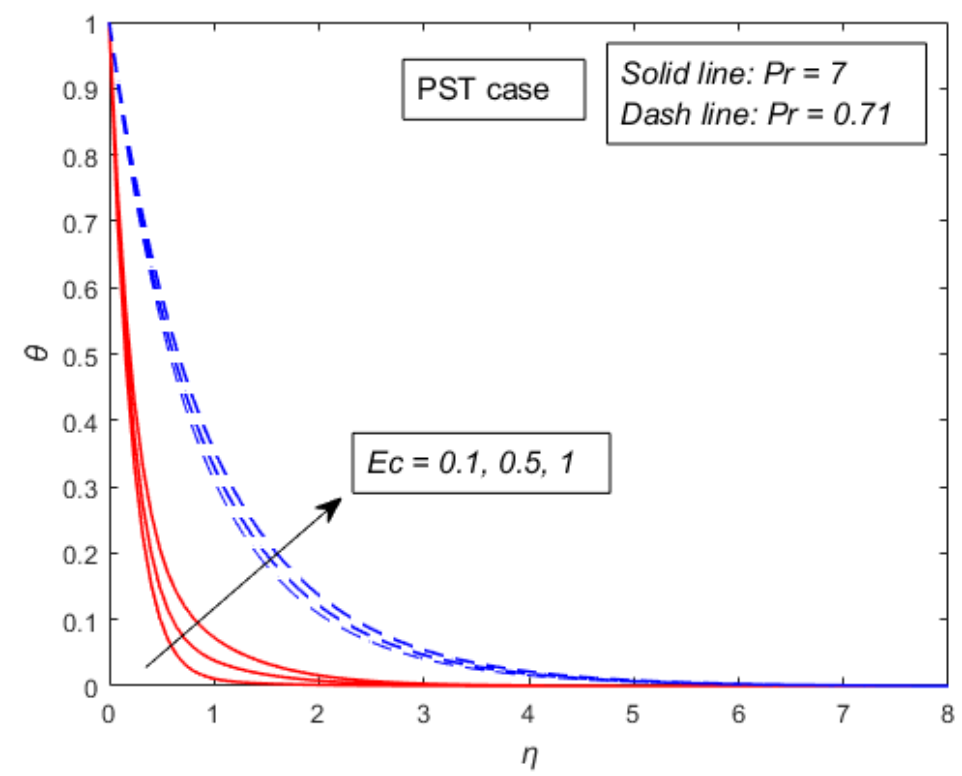

Figure 10. Variation of the temperature profile for different values of Eckert number Ec and Prandtl number $\operatorname{Pr}$ for the PST case when $n=3, K=1$, and $M=2$. 


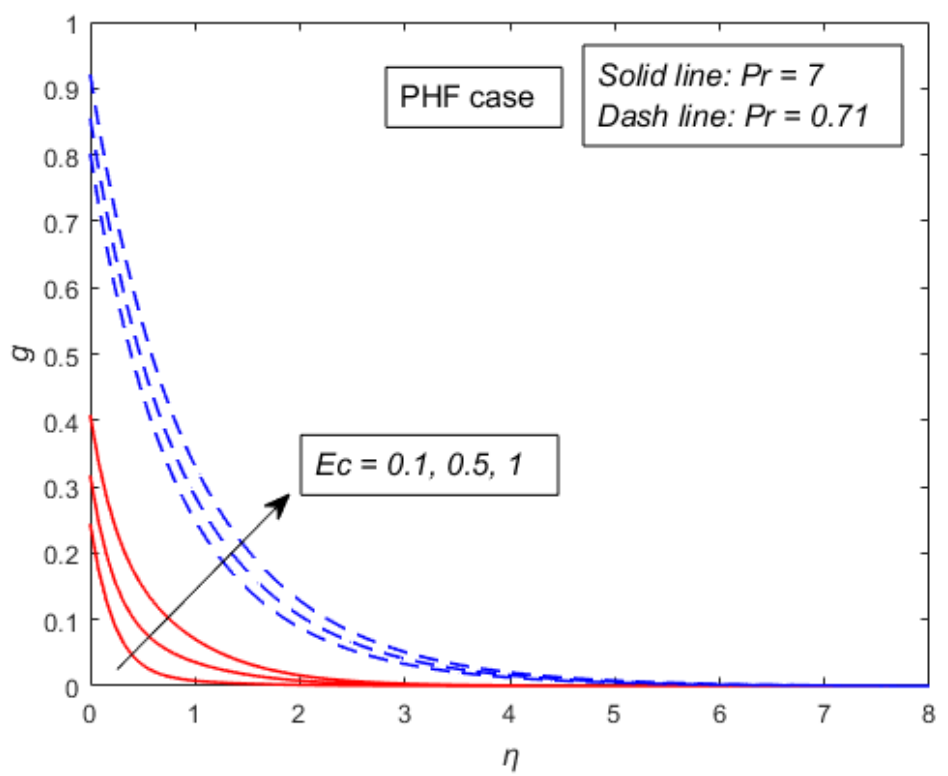

Figure 11. Variation of the temperature profile for different values of Eckert number Ec and Prandtl number $\operatorname{Pr}$ for the PHF case when $n=3, K=1$, and $M=0$.

Figures 12 and 13 are the plots of $\theta(\eta)$ and $g(\eta)$ with respect to $\eta$ for various values of $\operatorname{Pr}$ in the presence and absence of the Eckert number. It is clearly evident from these figures that an increase in $\operatorname{Pr}$ decreases the temperature profiles in the PST and PHF cases, respectively. This implies that the thickness of the thermal boundary layer is augmented with the decrease in the value of the Prandtl number. This is in close agreement with the results of Arnold et al. [43]. Physically, an increase in the Prandtl number will cause heat transfer enhancement, and this is consistent with the fact that the thickness of the thermal boundary reduces with an increase in $\mathrm{Pr}$.

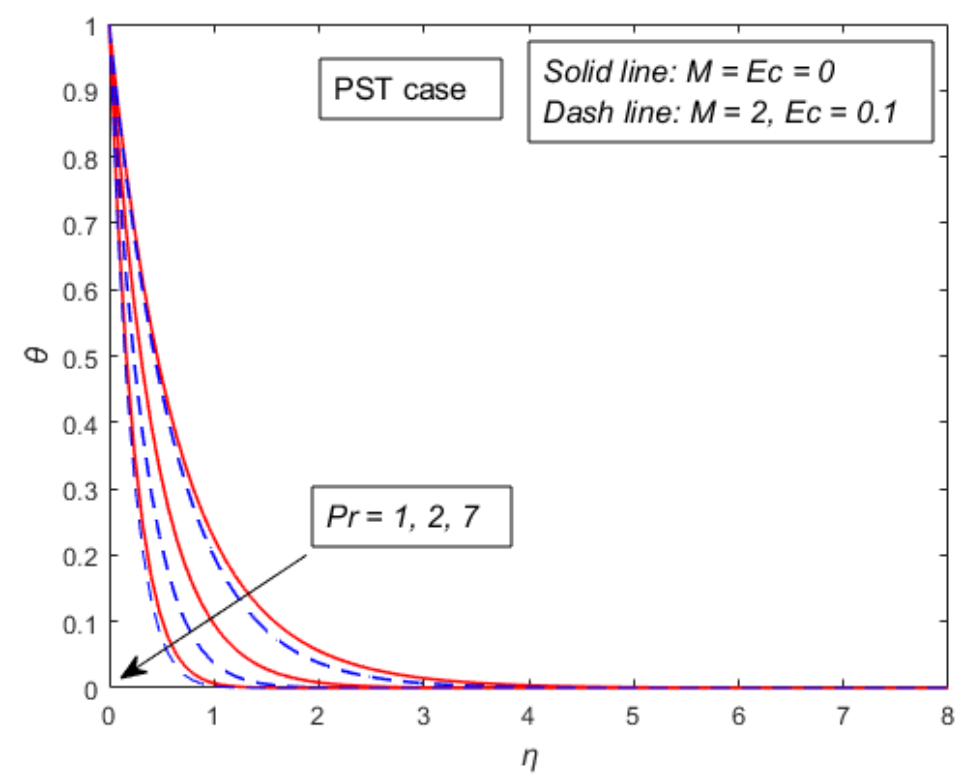

Figure 12. Variation of the temperature profile for different values of Prandtl number $\mathrm{Pr}$, Eckert number $E c$, and magnetic parameter $M$ on the temperature profile for the PST case when $n=3$ and $K=1$. 


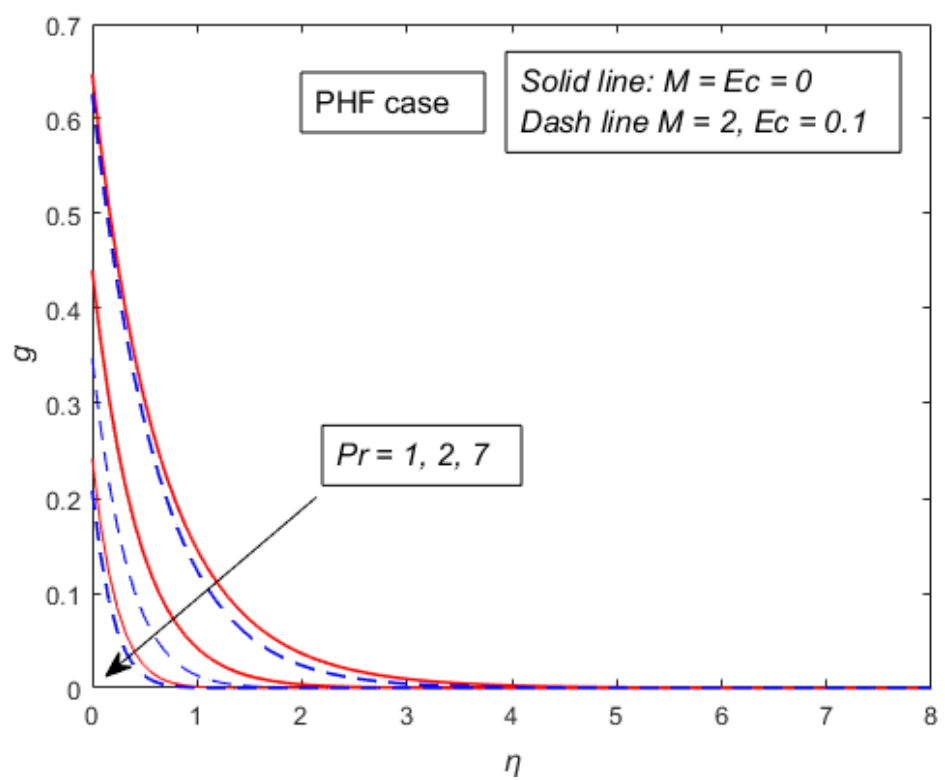

Figure 13. Variation of the temperature profile for different values of Prandtl number Pr, Eckert number $E c$, and magnetic parameter $M$ on the temperature profile for the PHF case when $n=3$ and $K=1$.

\section{Conclusions}

The numerical solutions for the two-dimensional boundary layer flow of a viscoelastic fluid and heat transfer past a nonlinear stretching sheet in the presence of magnetic field $M$ and viscous dissipation $E c$ for prescribed surface temperature (PST) and prescribed heat flux (PHF) were studied in this paper. The dimensional equations that govern the flow problem were reduced into nonlinear ordinary differential equations with the aid of an appropriate similarity transformation for nonlinear stretching sheet. The reduced equations were then solved numerically by the Keller box method. The effects of nonlinear stretching parameter $n$, viscoelastic parameter $K$, magnetic parameter $M$, Eckert number Ec, and Prandtl number $P r$ on the viscoelastic fluid and the characteristics of heat transfer were examined. The results for different values of $n, K$, and $\operatorname{Pr}$ were compared with the earlier results reported by Vajravelu [7] and Arnold et al. [43] for skin friction coefficient $f^{\prime \prime}(0)$, heat transfer rate $\theta^{\prime}(0)$, and surface temperature $g(0)$ in the case of PST and PHF, respectively. The summary of the present results is shown below

- The effect of nonlinear stretching parameter $n$ was to reduce the thickness of the momentum boundary layer and increase the thermal boundary layer thickness in the PST and PHF cases. However, the rate of increase was higher in the PST case.

- The increase in the value of the magnetic parameter resulted in decreasing the velocity profile and increasing the temperature profiles in both cases.

- The influence of $n, M$, and $K$ was to increase the coefficient of skin friction with its increase.

- The magnitude of the rate of heat transfer reduced with an increase in $M, K$, and $E c$, thereby increasing the temperature of the fluid for the PST case. However, the decrease was more pronounced with a higher value of $\mathrm{Pr}$. Similarly, the temperature at the wall also decreased with the increase in these governing parameters for the PHF case.

- The effect of $\operatorname{Pr}$ was to reduce the thickness of the thermal boundary layer and the rate of heat transfer at the surface for the PST case.

- The surface temperature reduced with the increase in Pr for the PHF case. This implies that an increase the Prandtl number had a cooling effect on the surface. 
Author Contributions: A.B.J. modeled the problem and solve it; S.S. and I.U contributed to the discussion of the problem and writing the manuscript. All the authors read and approved the final version of the manuscript.

Funding: This work was funded by the Ministry of Education (MOE) and Research Management Centre-UTM, Universiti Teknologi Malaysia (UTM) for the financial support through vote numbers 5F004, 07G70, 07G72, 07G76 and 07G77.

Acknowledgments: The authors would like to thank the Ministry of Education (MOE) and Research Management Centre-UTM, Universiti Teknologi Malaysia (UTM) for this research, the anonymous reviewers and the Editor-in-Chief for the constructive comments that led to the fruitful improvement in the manuscript.

Conflicts of Interest: The authors declare no conflict of interest.

\section{References}

1. Mastroberardino, A.; Mahabaleshwar, U.S. Mixed convection in viscoelastic flow due to a stretching sheet in a porous medium. J. Porous Media 2013, 16, 483-500. [CrossRef]

2. Nayak, M.K. Chemical reaction effect on MHD viscoelastic fluid over a stretching sheet through porous medium. Meccanica 2016, 51, 1699-1711. [CrossRef]

3. Mukhopadhyay, S.; Gorla, R.S. Effects of partial slip on boundary layer flow past a permeable exponential stretching sheet in presence of thermal radiation. Heat Mass Transf. 2012, 48, 1773-11781. [CrossRef]

4. Crane, L.J. Flow past a stretching plate. Zeitschrift für Angewandte Mathematik und Physik ZAMP 1970, 21, 645-647. [CrossRef]

5. Gupta, P.S.; Gupta, A.S. Heat and mass transfer on a stretching sheet with suction or blowing. Can. J. Chem. Eng. 1977, 55, 744-746. [CrossRef]

6. Kumaran, V.; Ramanaiah, G. A note on the flow over a stretching sheet. Acta Mech. 1996, 116, $229-233$. [CrossRef]

7. Vajravelu, K. Viscous flow over a nonlinearly stretching sheet. Appl. Math. Comput. 2001, 124, $281-288$. [CrossRef]

8. Vajravelu, K.; Cannon, J.R. Fluid flow over a nonlinearly stretching sheet. Appl. Math. Comput. 2006, 181, 609-618. [CrossRef]

9. Cortell, R. Viscous flow and heat transfer over a nonlinearly stretching sheet. Appl. Math. Comput. 2007, 184, 864-873. [CrossRef]

10. Cortell, R. Fluid flow and radiative nonlinear heat transfer over a stretching sheet. J. King Saud Univ. Sci. 2014, 26, 161-167. [CrossRef]

11. Pal, D.; Mandal, G.; Vajravelu, K. MHD convection-dissipation heat transfer over a non-linear stretching and shrinking sheets in nanofluids with thermal radiation. Int. J. Heat Mass Trans. 2013, 65, 481-490. [CrossRef]

12. Sarpkaya, T. Flow of non-Newtonian fluids in a magnetic field. AIChE J. 1961, 7, 324-328. [CrossRef]

13. Andersson, H.I.; Bech, K.H.; Dandapat, B.S. Magnetohydrodynamic flow of a power-law fluid over a stretching sheet. Int. J. Non-Linear Mech. 1992, 27, 929-936. [CrossRef]

14. Cortell, R.A. note on magnetohydrodynamic flow of a power-law fluid over a stretching sheet. Appl. Math. Comput. 2005, 168, 557-566. [CrossRef]

15. Prasad, K.V.; Santhi, S.R.; Datti, P.S. Non-Newtonian power-law fluid flow and heat transfer over a non-linearly stretching surface. Appl. Math. 2012, 3, 425-435. [CrossRef]

16. Ullah, I.; Bhattacharyya, K.; Shafie, S.; Khan, I. Unsteady MHD mixed convection slip flow of Casson fluid over nonlinearly stretching sheet embedded in a porous medium with chemical reaction, thermal radiation, heat generation/absorption and convective boundary conditions. PLoS ONE 2016, 24, e0165348. [CrossRef] [PubMed]

17. Ullah, I.; Shafie, S.; Khan, I. MHD free convection flow of Casson fluid over a permeable nonlinearly stretching sheet with chemical reaction. Malays. J. Fundam. Appl. Sci. 2017, 13, 263-270. [CrossRef]

18. Hayat, T.; Qayyum, S.; Alsaedi, A.; Ahmad, B. Magnetohydrodynamic (MHD) nonlinear convective flow of Walters-B nanofluid over a nonlinear stretching sheet with variable thickness. Int. J. Heat Mass Transf. 2017, 110, 506-514. [CrossRef] 
19. Javed, T.; Ahmad, H.; Ghaffari, A. Influence of radiation on vertical wavy surface with constant heat flux: Using Keller box scheme. Alex. Eng. J. 2016, 5, 2221-2228. [CrossRef]

20. Mahapatra, T.R.; Nandy, S.K.; Vajravelu, K.; Van Gorder, R.A. Stability analysis of fluid flow over a nonlinearly stretching sheet. Arch. Appl. Mech. 2011, 81, 1087-1091. [CrossRef]

21. Rajagopal, K.R.; Na, T.Y.; Gupta, A.S. Flow of a viscoelastic fluid over a stretching sheet. Rheol. Acta 1984, 23, 213-215. [CrossRef]

22. Dandapat, B.S.; Gupta, A.S. Flow and heat transfer in a viscoelastic fluid over a stretching sheet. Int. J. Non-Linear Mech. 1989, 24, 215-219. [CrossRef]

23. Cortell, R. A novel analytic solution of MHD flow for two classes of visco-elastic fluid over a sheet stretched with non-linearly (quadratic) velocity. Meccanica 2013, 48, 2299-2310. [CrossRef]

24. Andersson, H.I. MHD flow of a viscoelastic fluid past a stretching surface. Acta Mech. 1992, 95, $227-230$. [CrossRef]

25. Char, M.I. Heat and mass transfer in a hydromagnetic flow of the viscoelastic fluid over a stretching sheet. J. Math. Anal. Appl. 1994, 186, 674-689. [CrossRef]

26. Prasad, K.V.; Pal, D.; Umesh, V.; Rao, N.P. The effect of variable viscosity on MHD viscoelastic fluid flow and heat transfer over a stretching sheet. Commun. Nonlinear Sci. Numer. Simul. 2010, 15, 331-344. [CrossRef]

27. Abel, M.S.; Siddheshwar, P.G.; Nandeppanavar, M.M. Heat transfer in a viscoelastic boundary layer flow over a stretching sheet with viscous dissipation and non-uniform heat source. Int. J. Heat Mass Transf. 2007, 50, 960-966. [CrossRef]

28. Abel, M.S.; Mahesha, N. Heat transfer in MHD viscoelastic fluid flow over a stretching sheet with variable thermal conductivity, non-uniform heat source and radiation. Appl. Math. Modell. 2008, 32, 1965-1983. [CrossRef]

29. Mustafa, M. Viscoelastic flow and heat transfer over a non-linearly stretching sheet: OHAM Solution. J. Appl. Fluid Mech. 2016, 9, 1321-1328. [CrossRef]

30. Abel, M.S.; Sanjayanand, E.; Nandeppanavar, M.M. Viscoelastic MHD flow and heat transfer over a stretching sheet with viscous and ohmic dissipations. Commun. Nonlinear Sci. Numer. Simul. 2008, 13, 1808-1821. [CrossRef]

31. Cortell, R. Effects of viscous dissipation and radiation on the thermal boundary layer over a nonlinearly stretching sheet. Phys. Lett. A 2008, 28, 631-636. [CrossRef]

32. Medikare, M.; Joga, S.; Chidem, K.K. MHD stagnation point flow of a Casson fluid over a nonlinearly stretching sheet with viscous dissipation. Am. J. Comput. Math. 2016, 23, 37-48. [CrossRef]

33. Ramandevi, B.; Reddy, J.R.; Sugunamma, V.; Sandeep, N. Combined influence of viscous dissipation and non-uniform heat source/sink on MHD non-Newtonian fluid flow with Cattaneo-Christov heat flux. Alex. Eng. J. 2018, 57, 1009-1018. [CrossRef]

34. Atif, S.M.; Hussain, S.; Sagheer, M. Effect of viscous dissipation and Joule heating on MHD radiative tangent hyperbolic nanofluid with convective and slip conditions. J. Braz. Soc. Mech. Sci. Eng. 2019, 41, 189. [CrossRef]

35. Beard, D.W.; Walters, K. Elastico-viscous boundary-layer flows I. Two-dimensional flow near a stagnation point. Math. Proc. Camb. Philos. Soc. 1964, 60, 667-674. [CrossRef]

36. Madani Tonekaboni, S.A.; Abkar, R.; Khoeilar, R. On the study of viscoelastic Walters' B fluid in boundary layer flows. Math. Probl. Eng. 2012, 2012, 861508. [CrossRef]

37. Jaluria, Y. Natural Convection: Heat and Mass Transfer; Pergamon: Oxford, UK, 1980; Volume 5.

38. Ahmed, N.; Sharma, D.; Deka, H. MHD mixed convection and mass transfer from an infinite vertical porous plate with chemical reaction in presence of a heat source. Appl. Math. Sci. 2012, 6, 1011-1020.

39. Xu, H.; Liao, S.J. Series solutions of unsteady magnetohydrodynamic flows of non-Newtonian fluids caused by an impulsively stretching plate. J. Non-Newton. Fluid Mech. 2005, 29, 46-55. [CrossRef]

40. Kasim, A.M. Convective Boundary Layer Flow of Viscoelastic Fluid. Ph.D. Thesis, Universiti Teknologi Malaysia, Skudai, Johor, Malaysia, 2014.

41. Cebeci, T.; Bradshaw, P. Physical and Computational Aspects of Convective Heat Transfer; Springer Science Business Media: New York, NY, USA, 2012. 
42. Sarif, N.M.; Salleh, M.Z.; Nazar, R. Numerical solution of flow and heat transfer over a stretching sheet with Newtonian heating using the Keller box method. Procedia Eng. 2013, 53, 542-554. [CrossRef]

43. Arnold, J.C.; Asir, A.A.; Somasundaram, S.; Christopher, T. Heat transfer in a viscoelastic boundary layer flow over a stretching sheet. Int. J. Heat Mass Transf. 2010, 53, 1112-1118. [CrossRef]

(C) 2019 by the authors. Licensee MDPI, Basel, Switzerland. This article is an open access article distributed under the terms and conditions of the Creative Commons Attribution (CC BY) license (http://creativecommons.org/licenses/by/4.0/). 